\title{
Building a Learning Progression for Celestial Motion: Elementary Levels from an Earth-Based Perspective
}

\author{
Julia D. Plummer, ${ }^{1}$ Joseph Krajcik ${ }^{2}$ \\ ${ }^{1}$ College of Arts, Humanities, and Social Sciences, Arcadia University, Glenside, Pennsylvania \\ ${ }^{2}$ School of Education, University of Michigan, Ann Arbor, Michigan
}

Received 15 June 2008; Accepted 7 November 2009

\begin{abstract}
Prior research has demonstrated that neither children nor adults hold a scientific understanding of the big ideas of astronomy, as described in standards documents for science education [National Research Council [1996]. National science education standards. Washington, DC: National Academy Press; American Association for the Advancement of Science [1993]. Benchmarks for science literacy. New York: Oxford University Press]. This manuscript focuses on ideas in astronomy that are at the foundation of elementary students' understanding of the discipline: the apparent motion of the sun, moon, and stars as seen from an earth-based perspective. Lack of understanding of these concepts may hinder students' progress towards more advanced understanding in the domain. We have analyzed the logic of the domain and synthesized prior research assessing children's knowledge to develop a set of learning trajectories that describe how students' initial ideas about apparent celestial motion as they enter school can be built upon, through successively more sophisticated levels of understanding, to reach a level that aligns with the scientific view. Analysis of an instructional intervention with elementary students in the planetarium was used to test our initial construction of the learning trajectories. This manuscript presents a first look at the use of a learning progression framework in analyzing the structure of astronomy education. We discuss how this work may eventually lead towards the development and empirical testing of a full learning progression on the big idea: how children learn to describe and explain apparent patterns of celestial motion. (C) 2010 Wiley Periodicals, Inc. J Res Sci Teach 47: 768-787, 2010
\end{abstract}

Keywords: astronomy; achievement; field trips/excursions; performance assessment; elementary

Science is one of many areas that compete for children's educational time in school. It is therefore important for educators to identify the concepts that are central to each domain of science and build curriculum around those "big ideas," helping us weed out peripheral ideas and instruction that focuses on the rote memorization of disconnected facts. Big ideas hold broad explanatory power in the domain, make connections across isolated concepts, and have the potential to be developed over time as learners understanding them in increasingly sophisticated ways (Anderson, 2008; Duschl, Schweingruber, \& Shouse, 2007; Smith, Wiser, Anderson, \& Krajcik, 2006). Although the field is at the beginning of identifying what constitutes a "big idea" in each discipline, we argue that one big idea in astronomy for elementary and middle school students is that observable celestial phenomenon can be explained through the unobservable motions of the earth and moon. By the end of middle school, students should be able to apply this big idea to explaining the apparent daily motion of the sun, moon, and stars, explaining how the seasonal change of the sun's path leads to an explanation for the seasons, and explaining how the motion of the earth and moon relates to the phases of the moon (American Association for the Advancement of Science, 1993; National Research Council, 1996).

A learning progression describes one potential pathway between the initial knowledge children first bring to school and the big idea (for a recent discussion of learning progressions, see Corcoran, Mosher, \& Rogat, 2009; Hmelo-Silver \& Duncan, 2009). Along this pathway, students become more proficient,

\footnotetext{
Contract grant sponsor: National Science Foundation; Contract grant number: ESI 0227557.

Correspondence to: J. D. Plummer; E-mail: plummerj@arcadia.edu

DOI 10.1002/tea.20355

Published online 8 January 2010 in Wiley Online Library (wileyonlinelibrary.com).
} 
demonstrating "successively more sophisticated ways of reasoning" within that content area (Smith et al., 2006, p. 3). A learning progression is designed around the big ideas of the discipline, which can be introduced in their simplest form at an early age and "progressively refined, elaborated, and extended throughout schooling" (Smith et al., 2006, p. 5). Movement along a learning progression is highly dependent on the instructional interventions that students experience; all students will not move through this progression in the same order, nor will they all achieve the scientific understanding (Hmelo-Silver \& Duncan, 2009). Because of this, Stevens, Delgado, and Krajcik (2009) suggest that all learning progressions are hypothetical, even when empirically validated.

Identifying the conceptual areas that children find most challenging to learn is central to developing a learning progression (Duschl et al., 2007; Heritage, 2008; Smith et al., 2006). Research across many areas of astronomy (e.g., seasons, phases of the moon, earth shape and gravity) clearly shows that the nature of basic astronomical phenomenon is not well understood by most students, both in terms of their observational qualities and explanatory models (for reviews, see Adams \& Slater, 2000; Agan \& Sneider, 2004; Bailey \& Slater, 2003; Kavanagh, Agan, \& Sneider, 2005). Prior work on the development of learning progressions have focused on concepts that are interdisciplinary and foundational for a broad range of topics: atomicmolecular theory (Smith et al., 2006; Talanquer, 2009), evolution (Catley, Lehrer, \& Reiser, 2005), environmental literacy (Anderson, 2008; Mohan, Chen, \& Anderson, 2009), biodiversity (Songer, Kelcey, \& Gotwals, 2009), and genetics (Duncan, Rogat, \& Yarden, 2009). In contrast to these progressions, many important topics of elementary and middle school astronomy are highly contextual-primarily focusing on observations and properties of the specific astronomical bodies in our solar system, making learning progressions for elementary astronomy distinct from many other areas of science (however, additional big ideas that have more far reaching implications do eventually intersect with this conceptual area, such as the nature of light and spatial reasoning, as well as the potential for inquiry reasoning skills (Songer et al., 2009)).

\section{Development of the Learning Trajectories}

Our eventual goal is to develop a learning progression for the following big idea in astronomy:

Astronomical phenomena observed from an earth-based perspective (such as the patterns of apparent daily motion, seasonal changes, and the phases of the moon) can be explained using the earth's rotation and tilt, the earth's orbit around the sun, and the moon's orbit around the earth.

We chose to begin this work by focusing on the earth-based observational topics, those concepts that are necessary for students to understand order to move towards the more advanced explanations for their observations: the sun, moon, and stars appear to move slowly across the sky with a regular pattern of motion on a daily basis and the moon's appearance changes slowly over a month. These observational patterns are an appropriate starting point for elementary students' astronomy instruction as they describe the world from the child's earth-based perspective (AAAS, 1993; NRC, 1996). A scientific explanation for these concepts includes understanding how our perspective changes as the earth rotates on its tilted axis while slowly orbiting the sun, and understanding how the apparent motion and appearance of the moon changes as it slowly orbits the earth once a month. Over the course of a 24-hour day, the earth's rotation causes the sun, moon, and stars to all appear to rise and set, with the exception of those stars that appear to continually circle around the celestial pole. In northern latitudes, the sun's path is angled towards the south and never passes through the zenith, the point directly overhead. As the earth orbits the sun, this path shifts so that in the winter the sun's path is a short low path across the southern sky. As we move towards summer, the sun rises and sets progressively farther north while its altitude in the sky shifts higher and higher. The sun's path in summer and winter are shown in Figure 1. The moon's path is similar to the sun's path across the sky. However, the moon rises and sets progressively later over the course of its 28-day cycle. During this time, the appearance of the moon changes as it moves through its phases, showing more or less of its illuminated side. The angle of the stars' path across the sky is the same as the sun and moon. Over the course of the night we see stars appearing to rise in the east and set in the west allowing us to see different stars across the night. When the sun rises, the stars continue their apparent motion, but are not visible in the brightness of the daytime sky. 


\section{Path of the Sun}

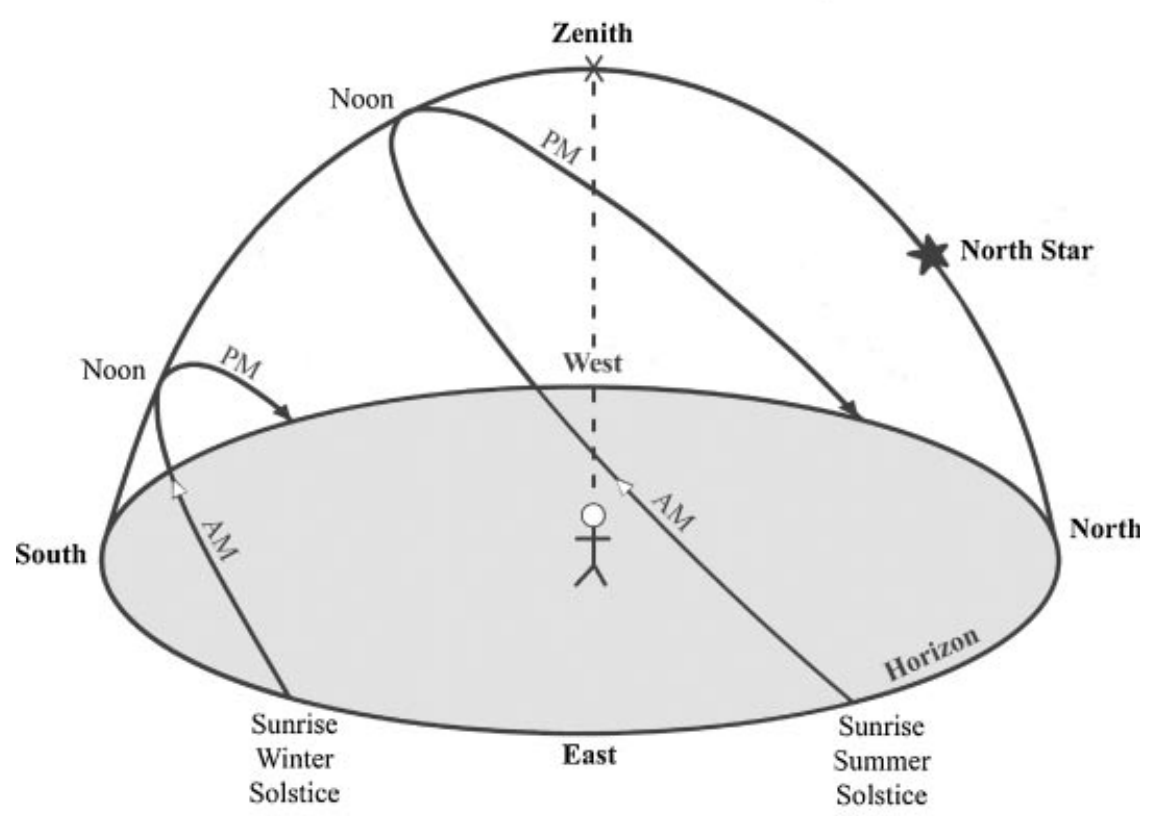

Figure 1. The sun's path in summer and winter for an observer at $40^{\circ}$ north latitude.

Rather than developing a complete learning progression for the full model of celestial motion describe above, we have developed a set of learning trajectories for apparent celestial motion, demonstrating how children may progress in understanding of the earth-based observational patterns that are part of the full learning progression. The mathematics education community has employed the use of learning trajectories to describe how children may move along a path towards goals in a specific mathematical domain through a proposed instructional intervention (Gravemeijer, 2004; Simon, 1995; Simon \& Tzur, 2004). The construction of these learning trajectories is similar to the process of creating learning progressions; a hypothetical learning trajectory is designed around learning goals, targeted activities, and a description of how students' thinking will develop in the context of the proposed instructional environment (Clements \& Sarama, 2004; Simon, 1995). We found learning trajectories to be a useful tool in describing our work on celestial motion because the focus is on a smaller grain-size than current learning progression work (Duschl et al., 2007; Heritage, 2008; Hmelo-Silver \& Duncan, 2009; Smith et al., 2006).

The apparent celestial motion learning trajectories we propose cannot be expressed as a single continuum describing increasing sophistication in understanding. Rather, apparent celestial motion is best described as four separate patterns, each with their own inter-related explanatory models:

(1) The sun's path is a smooth arc across the sky that slowly changes in length and altitude across the seasons.

(2) The moon moves across the sky on a daily basis in a similar path to the sun, sometimes during the day and sometimes at night.

(3) The pattern of stars remains the same but appear to move across the sky nightly. The stars visible after sunset change slowly across the seasons.

(4) The appearance of the moon changes slowly in a cycle that lasts about a month.

Each of these forms the basis of a separate learning trajectory, a research-supported ordered sequence of levels ranging from least to most sophisticated description of a characteristic, in this case an aspect of 
apparent celestial motion. The connection between these learning trajectories requires use of explanatory features not described here. Although, in some cases, the concepts may build on each other as successive levels of sophistication, in the area of apparent celestial motion, each learning trajectory is separate and distinct. Currently existing research, as well as our own research with students, allows us to create these learning trajectories for apparent celestial motion following a similar approach to other learning progression developments.

\section{Methodology}

Our development of the learning trajectories began with a close examination of the literature to identify children's ideas about celestial motion as they enter school and to understand how children may progress in understanding through traditional school experiences and observations of the world. Our search of the literature reveals a few relevant studies in this area: Sharp's (1996) report of 10- to 11-year-old English students' beliefs about apparent celestial motion; Trundle, Christopher, and Atwood's (2007b) study of American fourth grade students' ideas about the changing appearance of the moon; Mant and Summer's (1993) study of English primary school teachers' beliefs about apparent celestial motion; and Vosniadou and Brewer's (1994) study of the day/night cycle across American first, third, and fifth grade students. Although useful in identifying key areas of children's developing understanding, none of the previously mentioned studies gave enough details to fully develop a learning progression on apparent celestial motion. We primarily drew upon the first author's previous studies which focused directly on apparent celestial motion (Plummer, 2009a,b) and used the additional literature to support construction of the learning trajectories. Below, we will describe those studies and explain how they were used to construct the trajectories.

\section{Study A: A Cross-Age Study of Children's Knowledge of Apparent Celestial Motion}

Participants. The first study characterized American students' understanding of apparent celestial motion concepts in the first, third, and eighth grades, as learned through traditional schooling (though they had not studied astronomy during the study school year), observations of the world, and cultural interactions ( $N=20$ at each grade level; Plummer, 2009a). Participants were evenly split by gender, except for the first grade; only eight boys had signed permission letters, so an additional two girls were also interviewed. The first and third grade students attended the same public elementary school in a small town in the Midwestern U.S. The population attending this school was $96 \%$ Caucasian, $1 \%$ Native American, with other ethnicities forming the remaining $3 \%$. Eighteen percent of students at the school were eligible for free or reduced-price lunch. The eighth grade students attended a public middle school in nearby small Midwestern town. The population of this school was $97 \%$ Caucasian, $2 \%$ Hispanic, with the remaining $1 \%$ from other ethnicities. Twenty-eight percent of the students were eligible for free or reduced-price lunch.

The topics covered in the interview were selected primarily based on the astronomy concepts found in NSES and Benchmarks for early elementary grades. Categories and representative interview questions are included in Plummer (2009a). All interviews were conducted in a small dome whose interior represented the actual sky, like a small planetarium, by the first author of this study (see Figure 2). Students used a flashlight to demonstrate their ideas about apparent celestial motion on the interior ceiling of the dome. For the sun and moon's motion, students were asked to use the flashlight to demonstrate the motion twice, giving the student an opportunity to confirm the nature of their answer. Students generally showed consistency in their responses and appeared to have little difficulty in using the flashlight. Audio of each interview was recorded. Visual information from the students' demonstrations using the flashlight was drawn by the interviewer on a twodimensional dome template. Detailed diagrams were made for each student's answers for the path of the sun in summer and in winter, the path of the moon, and the motion of the stars (see Plummer, 2009a, for an example).

Data Analysis. The analysis of the interviews focused both the students' demonstrations and their verbal descriptions of these motions. For each category, codes were created which included both the accurate response and the possible non-normative ideas held by students (pulled both from the literature and created in the process of examining the data). The author coded all subjects while additional researcher coded a sample 


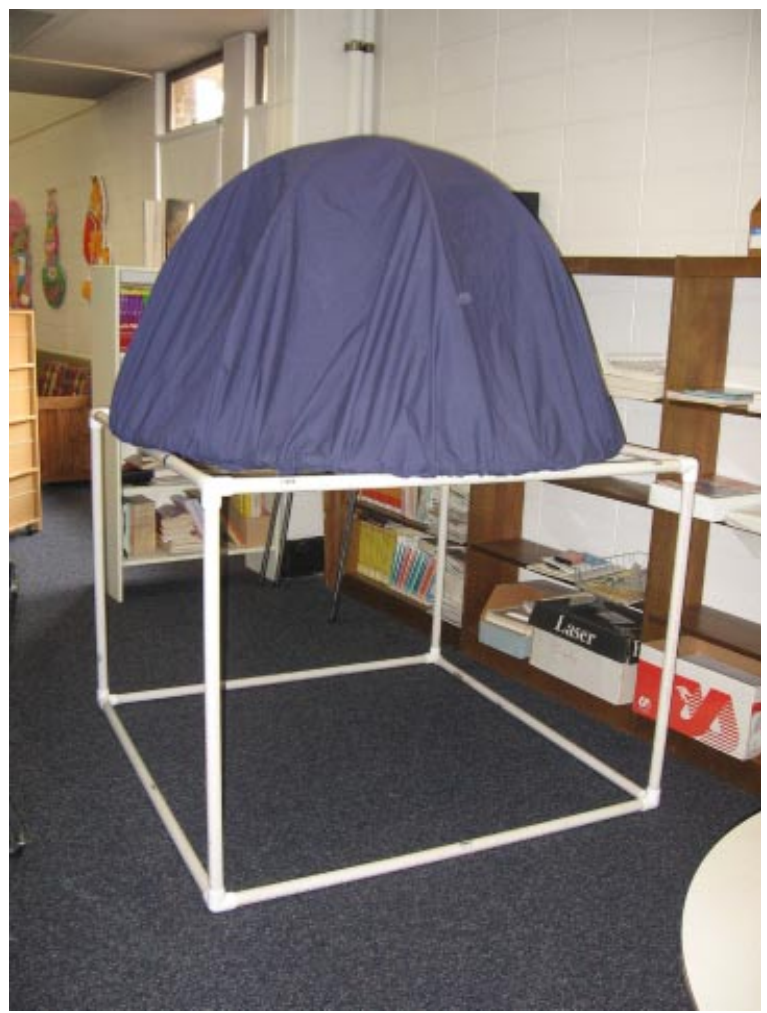

Figure 2. Dome used in the interviews.

of $15 \%$ of the students' responses, split evenly across the three grades. Inter-rater agreement was $86 \%$, calculated by computing the ratio of agreements to the total number of categories. Inconsistencies were discussed and resolved to improve coding reliability in the study.

\section{Study B: Elementary Students' Development of Astronomy Concepts in the Planetarium}

Data Collection and Analysis. The second study examined how children's ideas about celestial motion changed as the result of a planetarium program on celestial motion (Plummer, 2009b). Seven classes participated in the study. Four classes were a combination of first and second grade students from a small Midwestern city containing a university. The other three classes were second grade students from the same elementary school described in Study A. The majority of students in the study had previously attended a planetarium program prior to participation in the study.

Ten students from each classroom were randomly selected or selected by the teacher (chosen for a range in abilities) to be interviewed (split evenly by gender). Attrition due to absences resulted in a total of 63 students interviewed before and after the planetarium visit. Participants included 16 students in first grade (7 female, 9 male) and 47 students in second grade ( 23 female, 24 male). Interviews were coded using the same procedures as described for Study A. Inter-rater agreement was calculated between the two coders by computing the ratio of agreements to the total number of categories. There was a $92 \%$ agreement between the two raters.

Instructional Context. A 45-minute planetarium program on apparent celestial motion was designed to build on children's prior knowledge of celestial motion and to engage students as active participants in the program. Activities were designed that would directly address common alternative descriptions of celestial 
motion held by early elementary children (found in Study A). The students participated in the planetarium program, taught by the first author of this study, by using their own motions through the use of kinesthetic learning techniques (KLTs). First, the children used their hands and arms to make predictions about what the apparent motion of the sun, moon, and stars would look like in the sky. Second, the children were asked to point to and then follow the motion of objects as these were demonstrated throughout the program. The KLTs promote learning by offering an alternative modality for accessing the descriptions of celestial motion and focusing children's attention on the key topics (Clark \& Paivio, 1991; Plummer, 2009b).

The program cycled through repeated demonstrations of the daily motion of the sun, moon, and stars over several days, utilizing the planetarium's ability to show long periods of time quickly (full description in Plummer, 2009b). The program began with the students interacting both visually and kinesthetically with the sun's daily apparent motion concept. Students made predictions of the sun's path with their arms and then followed the sun with their arms as the planetarium projected its rising and setting motion across the sky. After the sun had set, students picked a bright star and traced its motion across the sky to emphasize that stars appear to rise and set as well.

During the next "day" in the planetarium, students focused on the sun's rising and setting position and apparent altitude to demonstrate that the sun does not pass directly overhead on the first day of summer at the students' latitude. The students had additional opportunities to make predictions and trace the sun's path. Again, after the sun had set, the students were asked to focus on a bright star and predict which stars would set first and which would stay in the sky as the night progressed.

To study the moon's apparent motion and changing appearance, the students followed the moon's rising and setting path when the moon was a thin crescent, first quarter phase, and full phase. The similarities between the moon's apparent motion and the sun's apparent motion were emphasized verbally and kinesthetically through tracing and predicting exercises. The show concluded with the students observing and tracing the sun's path on the first day of winter and then comparing that to their previous observations of its path on the first day of summer.

\section{Initial Construction of the Learning Trajectories Based on a Cross-Age Analysis}

We used primarily a qualitative approach towards the development of this set of learning trajectories beginning with unpacking the aspects of astronomy relating to the patterns of apparent celestial motion (Shin, Stevens, \& Krajcik, in press). By using the logic of the discipline, an examination of the scientific model describing celestial motion, we identified the concepts that form the end points of each proposed trajectory: what students should know from a scientific perspective about apparent celestial motion. This also allowed us to break down the end points into a succession of ideas that build on each other in increasing complexity towards the goal of a full scientific description. We focused on those descriptions that will support students in understanding more advanced topics in a full learning progression for celestial motion.

Next, we went beyond the findings of Study A to identify those concepts that children hold which are lacking in sophistication but could be built upon to reach the scientific understanding. These provided a starting point for the trajectories and potential intermediate stages. To order these lower and intermediate concepts, we first looked to the logic of the discipline to consider which concepts represent necessary knowledge towards the next higher level. We re-analyzed the data from Study A to uncover how the number of students who held these concepts changed across grade levels in order to establish each learning trajectory as a Guttman scale (Wilson, 2005). The lowest level includes concepts that most or all students held at all grade levels. Going through higher levels of each learning trajectory, the ideas become more sophisticated such that at the highest level no students held this level of knowledge, even by eighth grade.

\section{Refining the Learning Trajectories through Comparison with Instructional Outcomes}

The next step after creating a learning trajectory is to test its usefulness in describing student improvement after an instructional intervention and to consider how the student outcomes might influence the description and ordering of the trajectory. The instructional intervention in the planetarium primarily focused on the levels of least sophistication of the learning trajectory for two reasons (concepts found in Levels 1 and 2; see Figures 3-6). First, the planetarium program was only 45 minutes in length, limiting the breadth of 


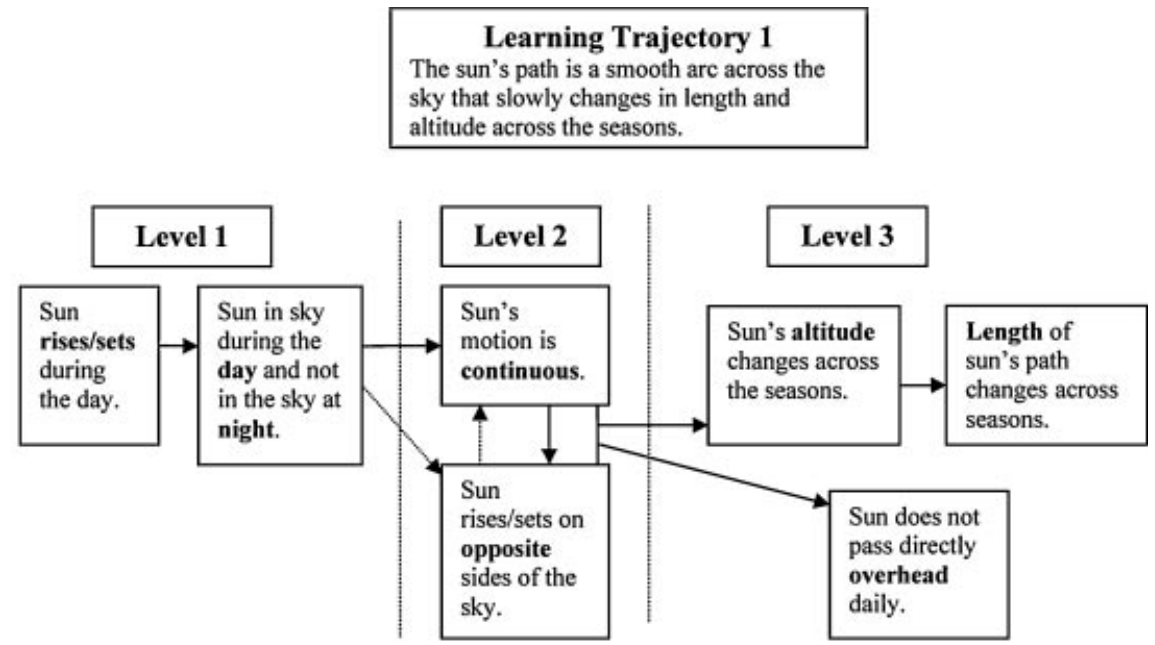

Percentage of students at each level for Study $A(N=60)$ and Study $B(N=63)$

\begin{tabular}{ccccccc}
\hline Level 1 & Level 1 & Level & Level & Level 3 & Level 3 & Level 3 \\
(Rise/set) & (Day/night) & 2 & 2 & (Overhead) & (Altitude) & (Length) \\
& & & & & & \\
& & & & & &
\end{tabular}

Study A

\begin{tabular}{cccccccc}
\hline $1^{\text {st }}$ grade & $65 \%$ & $79 \%^{2, b}$ & $60 \%$ & $30 \%$ & $0 \%$ & $0 \%$ & $0 \%$ \\
$3^{\text {rd }}$ grade & $95 \%$ & $75 \%{ }^{\mathrm{b}}$ & $90 \%$ & $70 \%$ & $0 \%$ & $0 \%$ & $0 \%$ \\
$8^{\text {th }}$ grade & $100 \%$ & $90 \%^{\mathrm{b}}$ & $95 \%$ & $100 \%$ & $5 \%$ & $10 \%$ & $0 \%$
\end{tabular}

Study B

\begin{tabular}{|c|c|c|c|c|c|c|c|}
\hline Before & $86 \%$ & $81 \%$ & N/A & $68 \%$ & $2 \%$ & $3 \%$ & $5 \%$ \\
\hline After & $97 \%$ & $86 \%$ & N/A & $86 \%$ & $54 \%$ & $59 \%$ & $57 \%$ \\
\hline
\end{tabular}

Figure 3. Learning trajectory for the apparent motion of the sun.

concepts that could be included in the instruction. Second, most children attending had not reached beyond the first level of each learning trajectory for many of these aspects of celestial motion.

In order to use the results of Study B to analyze how students moved along the learning trajectories, we returned to the original descriptive codes which were not reported; data in the published report had been primarily presented in terms of "scientific" or "non-normative" and through improvement scores (Plummer, 2009b). We then used the learning trajectory framework to re-analyze the descriptive codes from Study B into a similar format used by Study A (though primarily focusing on those concepts that we had already designated Journal of Research in Science Teaching 
Learning Trajectory 2

The moon moves across the sky on a daily basis in a similar path to the sun, sometimes during the day and sometimes at night.

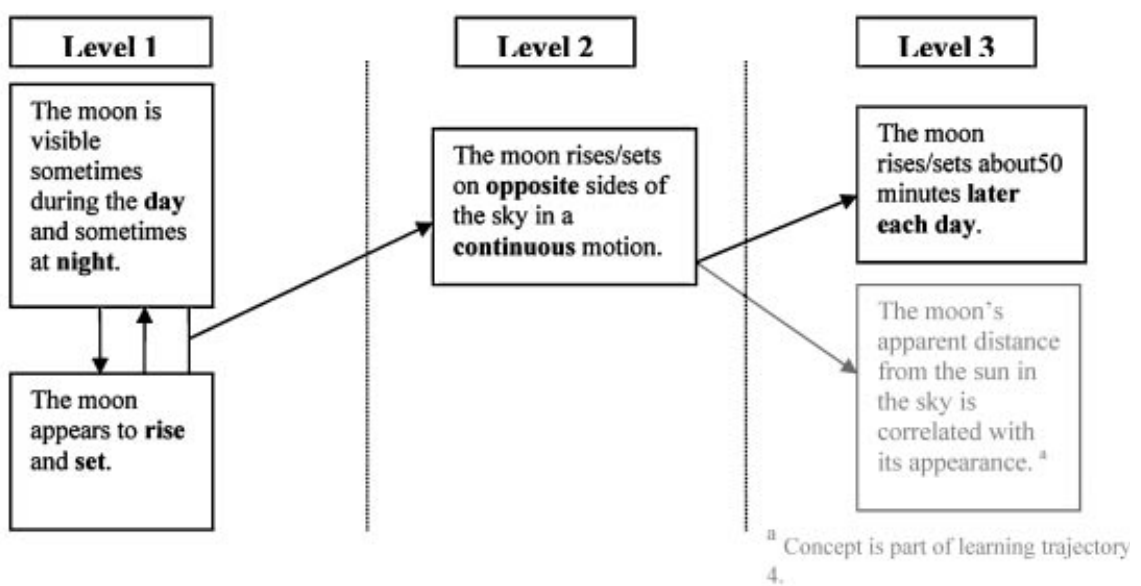

Percentage of students at each level for Study $A(N=60)$ and Study $B(N=63)$

\begin{tabular}{ccccc}
\hline & $\begin{array}{c}\text { Level 1 } \\
\text { (Day/Night) }\end{array}$ & $\begin{array}{c}\text { Level 1 } \\
\text { (Rise/Set) }\end{array}$ & $\begin{array}{c}\text { Level 2 } \\
\text { (Opposite) }\end{array}$ & $\begin{array}{c}\text { Level 3 } \\
\text { (Later each day) }\end{array}$ \\
\cline { 2 - 5 } & & & & \\
\hline $1^{\text {st }}$ grade & $60 \%$ & $45 \%$ & $5 \%$ & $\mathrm{n} / \mathrm{a}$ \\
$3^{\text {rd }}$ grade & $80 \%$ & $90 \%$ & $50 \%$ & $\mathrm{n} / \mathrm{a}$ \\
$8^{\text {th }}$ grade & $95 \%$ & $60 \%$ & $55 \%$ & $\mathrm{n} / \mathrm{a}$ \\
Study B & & & & \\
\hline Before & $76 \%$ & $81 \%$ & $57 \%$ & $\mathrm{n} / \mathrm{a}$ \\
After & $92 \%$ & $83 \%$ & $71 \%$ & $\mathrm{n} / \mathrm{a}$ \\
\hline
\end{tabular}

Figure 4. Learning trajectory for the apparent motion of the moon.

to be "productive" aspects of the learning trajectory). This analysis resulted in reordering a few of the higher levels of the trajectory (particularly in levels that the eighth grade students had not reached) and in some of the lower levels where instruction helped clarify differences in pre-instruction ordering (ordering suggested by first-grade data differed from the older grades).

Below, we will describe in detail each learning trajectory of apparent celestial motion. Within each of the figures describing our learning trajectories, arrows have been included that are directional, pointing towards higher levels, indicating that the initial concept is a necessary precursor to the concept at the end of the arrow. The up/down arrows between vertically aligned boxes indicate that for some concepts, the data does not 
Learning Trajectory 3

The pattern of stars remains the same but appear to move across the sky nightly. The stars we can see after sunset changes slowly across the seasons.

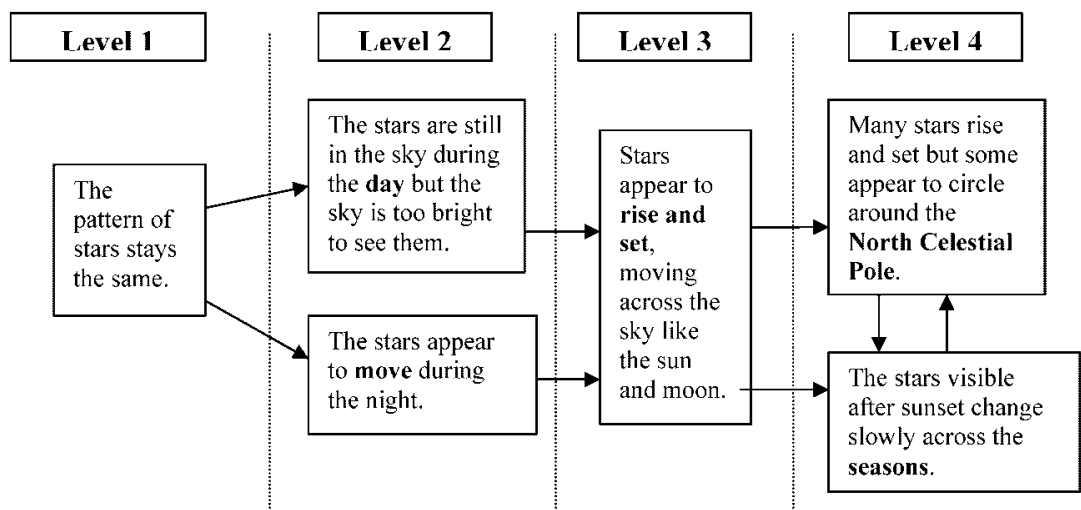

Percentage of students at each level for Study $A(N=60)$ and Study $B(N=63)$

\begin{tabular}{ccccccc}
\hline & Level 1 & $\begin{array}{c}\text { Level 2 } \\
\text { (Day) }\end{array}$ & $\begin{array}{c}\text { Level 2 } \\
\text { (Stars move) }\end{array}$ & $\begin{array}{c}\text { Level 3 } \\
\text { (rise/set) }\end{array}$ & $\begin{array}{c}\text { Level 4 } \\
\text { (NCP) }\end{array}$ & $\begin{array}{c}\text { Level 4 } \\
\text { (Seasons) }\end{array}$ \\
\cline { 2 - 7 } Study A & & & & & & \\
\hline $1^{\text {st }}$ grade & $\mathrm{n} / \mathrm{a}$ & $5 \%$ & $5 \%$ & $10 \%$ & $\mathrm{n} / \mathrm{a}$ & $\mathrm{n} / \mathrm{a}$ \\
$3^{\text {td }}$ grade & $\mathrm{n} / \mathrm{a}$ & $45 \%$ & $30 \%$ & $5 \%$ & $\mathrm{n} / \mathrm{a}$ & $\mathrm{n} / \mathrm{a}$ \\
$8^{\text {th }}$ grade & $\mathrm{n} / \mathrm{a}$ & $75 \%$ & $40 \%$ & $15 \%$ & $\mathrm{n} / \mathrm{a}$ & $\mathrm{n} / \mathrm{a}$ \\
Study B & & & & & & \\
\hline Before & $\mathrm{n} / \mathrm{a}$ & $54 \%$ & $30 \%$ & $11 \%$ & $\mathrm{n} / \mathrm{a}$ & $\mathrm{n} / \mathrm{a}$ \\
After & $\mathrm{n} / \mathrm{a}$ & $79 \%$ & $62 \%$ & $43 \%$ & $\mathrm{n} / \mathrm{a}$ & $\mathrm{n} / \mathrm{a}$ \\
\hline
\end{tabular}

Figure 5. Learning trajectory for the apparent motion of the stars.

indicate a preferred order in which students learn these concepts. With each figure, statistics showing the number of children at each level of the trajectory are given to support the ordering of concepts along the trajectory as drawn from a new analysis of the data collected for Study A and Study B.

\section{Learning Trajectories for Apparent Celestial Motion}

Learning Trajectory 1: The Sun's Path Is a Smooth Arc across the Sky That Slowly Changes in Length and Altitude across the Seasons

This learning trajectory describes features of the sun's motion that occur because of the earth's rotation, the earth's orbit around the sun on its tilted axis, and are mediated by our location on the curved surface of the earth (Figure 3). In the case of the students interviewed for this study, their location at 40 north latitude causes 


\section{Learning Trajectory 4}

The appearance of the moon changes slowly in a cycle that lasts about a month.

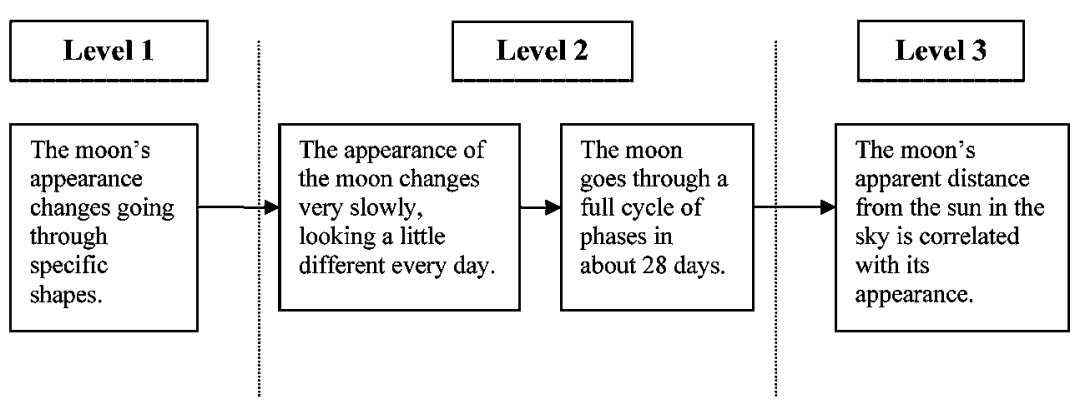

Percentage of students at each level for Study $A(N=60)$ and Study $B(N=63)$

\begin{tabular}{ccccc}
\hline & Level 1 & $\begin{array}{c}\text { Level 2 } \\
\text { (changes slowly) }\end{array}$ & $\begin{array}{c}\text { Level 2 } \\
\text { (phases) }^{\mathrm{a}}\end{array}$ & Level 3 \\
\cline { 2 - 5 } Study A & & & $5 \%$ & $\mathrm{n} / \mathrm{a}$ \\
\hline $1^{\text {st }}$ grade & $75 \%$ & $20 \%$ & $50 \%$ & $\mathrm{n} / \mathrm{a}$ \\
$3^{\text {rd }}$ grade & $100 \%$ & $55 \%$ & $70 \%$ & $\mathrm{n} / \mathrm{a}$ \\
$8^{\text {th }}$ grade & $90 \%$ & $75 \%$ & & \\
Study B & & & $37 \%$ & $\mathrm{n} / \mathrm{a}$ \\
\hline Before & $95 \%$ & $44 \%$ & $66 \%$ & $\mathrm{n} / \mathrm{a}$ \\
After & $98 \%$ & $67 \%$ & $67 \%$
\end{tabular}

\footnotetext{
${ }^{\mathrm{a}}$ Students were accurate if the appearance of the moon changed on the order of days or up to a month.
}

Figure 6. Learning trajectory for the change in the appearance of the moon.

the sun to appear to rise and set every day at an angle slanted towards the south, never passing through the zenith position. The path of the sun becomes shorter and shifts further south as we move towards winter and then lengthens and moves further north heading towards summer.

Development Based on Study A. Level 1: Whether or not a student believes that the sun appears to move in the sky during the day may influence how they explain the occurrence of day and night (Vosniadou \& Brewer, 1994). Students who do not make these observations about the sun's apparent change in position during the day may also not believe that the sun is "down" at night. Instead, they may explain the sun's disappearance at night by saying that the sun is behind clouds, behind the moon, or has moved out into space (Baxter, 1989; Vosniadou \& Brewer, 1994). This suggests that there may be a link between how children's changing understanding of the sun's apparent motion depends on their beliefs about its day- and nighttime location. We assessed children's understanding about whether or not the sun is still in the sky at night based on their answers to the question: "Where is the sun at night when we can't see it?" 
We initially hypothesized that children would first believe that the sun is in the sky during the day and not in the sky at night and would then develop the concept that during the day the sun appears to rise up and then set at the end of the day. However, this order was not supported by the students' actual beliefs. Among the first grade students, more knew that the sun is in the sky during the day but not at night than that the sun rises and sets (Figure 3). This balance reversed for the third and eighth grade students as well as the students both before and after the planetarium program (discussed further below). This suggests that perhaps some children first learn that the sun is in the sky and gone at night but later more children learn that the sun rises and sets.

The second aspect of this level involves understanding that during the day, the sun gets higher in the sky and then lower, though the exact path is not necessarily accurate and the sun may rise and set in the same place along the horizon. While many of the first grade students (35\%) describe the sun as rising and setting, nearly all third grade students could give this description (95\%). This suggests that early elementary students are likely to easily acquire this level of knowledge, possibly through guided observations by their parents and teachers. Such observations could include the sun appearing low in the sky in the morning, high in the sky later in the day, and then low in the sky at the end of the day. Knowledge of these changes in the sun's apparent position are likely to help students to form the next concept in the trajectory.

Level 2: The next two aspects of developing understanding of the sun's apparent motion were based on trends observed in Study A. Some children understood that the sun rises and sets in a continuous motion while others believed that the sun would rise, stay at the top of the sky, and then set, suggesting that continuous motion represents one aspect of a more sophisticated understanding of the scientific description. Other students did not understand that the sun rises and sets on opposite sides of the sky. Acquiring each of these concepts requires a complex set of observations if a child is to learn this from his or her own observations. While a child may notice that the sun appears successively higher from morning until the middle of the day and then lower at the end of the day, the observations necessary to conclude that this motion took the sun across the sky (rather than just up and down on one side of the sky) require comparing the sun's position to fixed points along the horizon.

The data suggest that learning one concept (the sun moves continuously) does not seem to depend on learning the other (the sun moves from one side of the sky to the other). In first grade, the majority of the children did not demonstrate that the sun moves continuously across the sky though some knew that the sun rises and sets on opposite sides of the sky. The third grade students knew that the sun does not remain unmoving at the top of the sky although a large fraction of children did not know that the sun does not rise and set on opposite sides of the sky. This may be due to a lack of experience in observing the location of where the sun rises and sets or because children are still developing their spatial orientation abilities (Roberts \& Aman, 1993).

Level 3: The concepts described in Levels 1 and 2 are those that the eighth grade students had already mastered. None of the eighth grade students demonstrated full understanding of the concepts at Level 3 (the sun does not pass directly over one's head everyday and that the sun's path gets longer and higher as the observer's hemisphere moves from winter to summer). Students were only included in Level 3 if their descriptions of the sun's apparent motion also included accurate Level 2 responses.

The concept that "the sun does not pass directly overhead" is the next logical step for students to learn after they understand that the sun's apparent motion can be described as a smooth arc across the sky because it makes modifications to that basic notion. Previous surveys of middle school (Trumper, 2001a) and high school students (Lightman \& Sadler, 1993; Trumper, 2001b) found that the majority of students believe that the sun passes directly overhead, a misconception perpetuated by the everyday saying that the sun is "overhead." None of the first grade students and a few of the older students (20\% in third and $10 \%$ in eighth grade) demonstrated that the sun does not pass directly overhead in summer and winter (these students live in northern latitudes where the sun never reaches an altitude higher than $73.5^{\circ}$ ). However, only one of the eighth grade students also accurately described the sun's path across the sky.

The seasonal change in the length and altitude of the sun's path also appears to be a challenging concept for students to master using traditional instruction and experiences. First grade students can be characterized as primarily moving into Level 1. Many third grade students and most eighth grade students had achieved a Level 2 description of the patterns of motion. None of the students had reached a full understanding of Level 3. 
Instructional Intervention for Learning Trajectory 1. Prior to the planetarium program, the first and second grade students in Study B held similar beliefs to the first grade students of Study A (Figure 3). The majority of students (68\%) understood Level 1 concepts as well as the Level 2 concept that the sun rises and sets on opposite sides of the sky (continuity was not assessed in the coding for Study B). After planetarium instruction, $86 \%$ of the first and second grade students had reached Level 2, a significant improvement from before instruction. The first and second grade students in Study B showed significant improvement in understanding that the sun does not pass directly overhead in the Midwestern U.S., a concept placed in Level 3. Without instruction, only one student indicated that the sun does not pass through the zenith during the summer; after the planetarium program 57\% accurately demonstrated that the sun does not pass through the zenith. Prior to instruction, a few students expressed knowledge of the change in the sun's path length (5\%) or change in altitude (3\%) across the seasons (only students who also understood Level 1 and 2 concepts were placed in Level 3). After instruction, $60 \%$ of students could accurately compare the length of the sun's path across summer and winter, and 63\% students gave an accurate description of the change in the sun's altitude. Thus this planetarium program helped over half of the students' progress to a Level 3 description of the motion of the sun, a more advanced description than given by middle school students in Study A. This highlights the importance of instruction on these topics; it is likely that the eighth grade students never received instruction targeted towards these concepts in a way that would allow them to perform these same descriptions.

\section{Learning Trajectory 2: The Moon Moves across the Sky on a Daily Basis in a Similar Path to the Sun, Sometimes during the Day and Sometimes at Night}

At first order, the moon's apparent motion is the same as the sun-rising and setting along the same angled path that depends on your location on the earth - because the motion is a result of the rotation of the earth. The moon's slow orbit causes the moon to rise approximately 50 minutes later every day and results in the slow changing of its appearance in the sky. Figure 4 shows the learning trajectory for students' understanding of the apparent motion of the moon.

Development of Learning Trajectory 2. Level 1: Children's early ideas about the moon include believing that the moon is only visible at night or at least that it is connected with the occurrence of night (Vosniadou \& Brewer, 1994). Many first grade students (40\%) in Study A still believe the moon can only be seen at night but by third grade most know the moon is visible during the day ( $80 \%$ of third grade students). Understanding that the moon can be seen both day and night will be important later for establishing the pattern of rise/set times for the moon and provide evidence that the moon must be slowly orbiting the earth.

As with the sun, the initial step in understanding apparent celestial motion of the moon is to describe the moon as appearing to rise and set. And while most first grade students believe the moon appears to move at night (85\%) less than half (45\%) of the students described this motion as a simple rise and then set. Ninety percent of the third grade students described the moon as rising and setting; however, only $60 \%$ of the eighth grade students indicated that the moon appears to rise and set.

About half of the first grade students (55\%) indicated the same pattern of motion for the moon as they had previously indicated for the sun. This may be connected to the common belief among young children that the moon and sun move opposite in the sky, with one rising as the other sets (Vosniadou \& Brewer, 1994) or simply because these are both celestial objects leading them to think they may appear to move the same. Half (50\%) of both third and eighth grade students used the same path for the sun and moon.

Level 2: At Level 2 of the learning trajectory students display an understanding that (a) the moon's motion is continuous and (b) the moon rises and sets on the opposite sides of the sky. However, we did not specifically separate these two concepts in the trajectory due to specific complexities in the students' answers. More first grade students believed that the moon rises and sets than believe that its motion is continuous, often showing the moon rising up, staying at the top of the sky, then setting at the end of the night (45\% vs. 30\%; Plummer, 2009a). Because many of the eighth grade students believed that the moon appears to circle around the sky, rather than rising and setting, they showed the opposite trend (60\% vs. 90\%; Plummer, 2009a). These inconsistencies across students of different ages led us to group the idea of continuous motion with the moon rising and setting on opposite sides of the sky. 
A shift towards Level 2 occurred by third grade. Half of third grade students in Study A (50\%) believed that the moon moves continuously across the sky (rising and setting on opposite sides of the sky) while the majority of the first grade students $(60 \%)$ believed that it remains at the top of the sky for an extended period of time. Eighth grade students' descriptions did not show improvement over the third grade students. While nearly all (90\%) gave a description of continuous motion, $35 \%$ of the eighth grade students believed that the moon remains in the sky during the day and night rather than rising and setting on opposite sides of the sky (10\% of third grade students held this notion). We propose three possibilities for the genesis of this shift towards less accurate descriptions of apparent motion as the result of inaccurate interpretations of instruction on the actual motion of the earth and moon. First, students who learn that the moon is visible in both the day and night may conclude the moon is visible every daytime and every nighttime leading them to conclude that the moon stays up all of the time. Second, when students learn that the moon orbits around the earth, they may interpret this to mean that the moon appears to circle around in our sky. Third, some students may have interpreted the concept "the moon stays in place but the earth rotates" to mean that the moon does not appear to move as well. Each of these possibilities suggests the need for care when teaching students about actual celestial motion to also include the consequences to apparent celestial motion.

Level 3: Two aspects of the moon's apparent pattern of motion are placed at Level 3: (1) the moon rises about 50 minutes later every day and (2) the moon's appearance changes as it is closer and further from the sun in the sky. The second concept is also placed in learning trajectory 4 and will be discussed later in this manuscript. Neither concept was assessed in Study A because these go beyond the basic levels of understanding for early elementary students.

Instructional Intervention for Learning Trajectory 2. Prior to the planetarium instruction in Study B, $19 \%$ of the students did not describe the moon's motion as a rising and setting and $24 \%$ of students did not believe that the moon can be seen during the daytime (Figure 4). Half (57\%) of students could be placed at Level 2: rising and setting on opposite sides of the sky with continuous motion. After planetarium instruction, the number of students who demonstrated Level 2 understanding increased to $71 \%$ of students accurately describing the moon as appearing in the day and night, demonstrating that the moon rises and sets across the sky and understanding the continuous nature of the moon's motion.

This study did not explicitly focus on teaching concepts relating to Level 3 (shift in the rise and set time) and therefore the children's understanding in this area was not assessed. Vosniadou and Brewer's (1994) study of first, third, and fifth grade students found that children often believe that the moon rises as the sun sets, and vice versa, despite knowing that we can see the moon in the sky during the day at times. Many children believe that the moon is causal in the occurrence of night. This suggests that it may be necessary to address children's full explanatory model to teach the concept that the moon rises and sets 50 minutes later every day.

\section{Learning Trajectory 3: The Pattern of Stars Remains the Same But Appear to Move across the Sky Nightly. The Stars Visible after Sunset Changes Slowly across the Seasons}

The third of the apparent celestial motion learning trajectories describes the motion of the stars during the night and how the pattern of stars we see changes across the seasons (Figure 5). The reason this apparent motion occurs is because the earth is surrounded by stars in every direction. The stars are at such a great distance that they do not appear to be moving with respect to each other, forming fixed patterns in the sky that we call constellations. As the earth rotates, the stars appear to rise and set throughout the night; this pattern continues throughout the daytime but we are unable to observe this because the scattering of sunlight in the atmosphere.

Development of the Third Learning Trajectory. Level 1: The concept placed at Level 1, the pattern of the stars stay the same, was not directly assessed in Study A. Understanding this concept could include beginning to learn about the constellations and will be a useful concept to establish before attempting to address the full extent of the pattern of apparent stellar motion. Further study is needed to confirm the progression of children's ideas in this area.

Level 2: Without well-designed instruction many children will not have an accurate understanding of the concepts at Level 2 of the learning trajectory by the end of elementary school: the stars are still in the sky 
during the day and the stars appear to move slowly during the night. Less than half (45\%) of the third grade students and $75 \%$ of eighth grade students understood that the stars are still in the sky during the day, but not visible because the sky is too bright. This is consistent with Vosniadou and Brewer's study (1994) which found that $45 \%$ of third grade students and $60 \%$ of fifth grade students knew there were stars in the sky during the day. To progress towards a more advanced understanding of the stars' apparent motion, students also need to develop a belief that the stars appear to move slowly during the night, though initially this may not include a full understanding that the stars rise and set. Less than half of the students believed that the stars appear to move at night (30\% of the third grade students and $40 \%$ of eighth grade students). Even fewer (14\%) of the 10- and 11-year-old students in Sharp's (1996) study believed that the stars appear to move (differences in interview techniques may explain this difference in percentages).

Level 3: Building on the concept of the stars' motion in Level 2, students at Level 3 understand that the stars' locations appear to change slowly, as they rise and set like the sun, but not a full description of the stars' pattern of motion (which would include understanding the circumpolar motion of stars near the celestial poles). Fifteen percent of the eighth grade students described a rising and setting motion for the stars, including the understanding that we would see different stars throughout the night; fewer students gave this level of accurate answer at the younger grades. The majority of eighth grade students (80\%) believed that we see the same stars all night long. This suggests that instruction needs to emphasize that we see different stars throughout the night because of the rising and setting motion of the stars. Studies of adults suggest that students are not learning this pattern of motion and that many are not aware that the stars appear to move at all (Mant \& Summers, 1993; Plummer, Zahm, \& Rice, accepted). Among the English primary school teachers interviewed by Mant and Summers, all were aware of the apparent motion of the stars but only $20 \%$ were able to describe that motion. In Plummer, Zahm, and Rice's study of American pre-service elementary teachers, only $50 \%$ believed that the stars appear to move and only $28 \%$ could describe that motion and explain that we would see different stars throughout the night.

Some students may find the apparent motion of the stars contradictory with the idea that stars are still in the sky during the day. Vosniadou and Brewer (1994) suggest, based on their interviews with elementary students, that students who think the stars do not move believe that they are still in the sky during the day and vice versa. This may also be why some of the first (30\%), third (10\%), and eighth grade students (10\%) suggested that the stars only move at the end of the night. If they believe there are no stars in the sky during the day (supported by their observations of the daytime sky) then they must explain that change by moving the stars out of the sky at the end of the night.

Level 4: The stars' apparent motion includes (a) the full description of the stars' apparent motion throughout the night and (b) the change in the stars we see over the seasons. The first concept builds on the goals of previous stages of the trajectory but it also relates to the students' understanding of the patterns of motion of the sun and moon. Once students have mastered the rising and setting patterns of the sun and moon, they may find it easier to describe the stars as exhibiting a similar pattern of motion. But developing this knowledge will require instruction that helps the students imagine the nature of this pattern of motion. The interviews with the eighth grade students, as well as studies of elementary in-service (Mant \& Summers, 1993) and pre-service teachers (Plummer et al., accepted) demonstrate that learners, through adulthood, are often unable to describe the stars' apparent motion without instruction.

The final aspect of the apparent motion of the stars is the concept that we see different stars after sunset during different seasons. By middle school, the NSES and Benchmarks recommend that students learn about the earth's orbit around the sun. However, we found no relevant research on children relating our observations of different stars across the seasons to other aspects of the stars' learning trajectory.

Instructional Intervention for Learning Trajectory 3. Prior to the planetarium instruction, students in Study B were assessed on their knowledge of the location of the stars during the day and night, and their apparent motion, but not concepts relating to Level 1. Most students (70\%) were at Level 1 or lower, based on their lack of understanding that the stars appear to move (Figure 5). Slightly more than half (54\%) of the students could give an accurate response to the Level 2 concept, location of the stars during the daytime. Only $11 \%$ of the students had reached Level 3 - understanding that the stars appear to rise and set during the night. Planetarium instruction helped move these students along the progression; over half had reached at least 
Level $2(62 \%)$ while $43 \%$ had reached at least Level 3, understanding that the rise and set of the stars means that we see different stars throughout the night.

The rising and setting motion of the stars would seem to be an area that the planetarium is particularly well suited. The fact that many children did not successfully reach Level 2 or 3 from this planetarium instruction may indicate the difficulty of this concept as well as the short length of the intervention. If students had previously studied the patterns of stars or the idea that the stars surround the earth, perhaps more students may have been successful. Instruction that improves students' understanding of the apparent motion of the stars but does not include the planetarium (or planetarium-like software on a computer) will be challenging to implement. Without the aid of a planetarium to demonstrate these motions on a faster time scale, instruction on the apparent motion of stars may require that students understand the reason why the stars appear to move: the rotation of the earth.

Teaching this concept from the perspective of the earth's rotation in a classroom may not be successful for many students if it is not explicitly taught. In a study of instruction that focused on the earth's rotation, Diakidoy and Kendeou (2001) found that after instruction 31\% of fifth grade students did not infer that the stars are still in the sky during the day. Their study did not explicitly assess the apparent motion of the stars, but without knowing that the stars are still in the sky during the day students are going to be limited in their ability to fully describe the stars' rising and setting motion. This suggests that instruction needs to account for children's mental models of the stars' location around the earth and address how the rotation of the earth relates to our observations of the stars (which were not part of Diakidoy and Kendeou's instruction).

Because most of the students targeted in this instruction were starting at Level 1 or below, Study B was not designed to address or assess concepts in Level 4.

\section{Learning Trajectory 4: The Appearance of the Moon Changes Slowly in a Cycle That Lasts about a Month}

The shape of the moon appears to change slowly over the course of 28 days before beginning the cycle again. As the moon orbits the earth we see first more of the side facing the sun and then less of the illuminated side. However, children in elementary school are likely to have difficulty understanding and using the explanation for the apparent change to the moon's appearance (Baxter, 1989; Kavanagh et al., 2005; Stahly, Krockover, \& Shepardson, 1999). The purpose of this learning trajectory is to suggest how children may build upon early observations to a complete understanding of the observational aspects of this change (Figure 6). If children have this full descriptive understanding of the phases of the moon they may be more successful in learning the explanations for the pattern of change.

Development of Learning Trajectory 4. Level 1: The majority of first grade students (75\%), all third grade students, and most of the eighth grade students (90\%) could be place at Level 1 by making at least two drawings of the shape of the moon and indicated that they were aware of the change in the moon's appearance.

Level 2: The steps at Level 2 build one upon the other: the moon's appearance changes very slowly and the moon goes through an entire cycle of phases in 28 days. Half of the third grade students (50\%) and $70 \%$ of eighth grade students had reached at least the first concept of Level 2, giving an accurate answer to the length of time it would take to observe a significant change to the moon's appearance. Most of the students with alternative ideas believed that this change could occur in minutes or hours. The question of the exactly length of the moon phase cycle was not asked in Study A.

Level 3: Study A did not examine the conceptual area at Level 3: when and how learners correlate the moon's apparent distance from the sun in the sky to its appearance. Lack of understanding of lower levels of the learning trajectory suggests that very few students will notice this pattern on their own.

Instructional Intervention for Learning Trajectory 4. Research on children and adults' understanding of the phases of the moon demonstrates how challenging it is to gain a scientific understanding of this phenomenon even with extended instruction (Barnett \& Morran, 2002; Baxter, 1989; Kavanagh et al., 2005; Stahly et al., 1999; Trundle, Christopher, \& Atwood, 2002, 2006, 2007a,b). We focus on how children learn to describe the changes in appearance without tying this to the explanation for the phenomenon. Almost all children in these studies knew the Level 1 concept that the moon's appearance changes and could draw at least 
two different phases, but prior to instruction, less than half of the children had reached Level 2 in their understanding of the timescale in which this change occurs. Over half (63\%) indicated inaccurate ideas about how long it takes for the moon to change phases (most believing that the moon's appearance changes significantly over the course of a single night). Planetarium instruction helped move students along the progression; after instruction, $66 \%$ accurately stated that it takes longer than a single night for the moon's appearance to change significantly. This instruction did not specifically teach children that the pattern of phases occurs every 28 days so this aspect of the learning progression was not assessed.

Trundle et al. (2007b) examined fourth grade children $(N=48)$ learning to describe and explain the changing phases of the moon. Their study used a more rigorous interpretation of children's drawings of the various phases of the moon than our work in order to examine how children's knowledge of the full cycle of phases of the moon improved through a 9-week observation period of the lunar phases. Prior to instruction, the majority of children knew that the moon has phases (though they did not have a fully articulated description of this changing appearance) and $81 \%$ of the students knew that the moon's changing appearance is in a predictable pattern. Instruction that included observations of the moon allowed $77 \%$ of the students to attempt to draw all of the major phases of the moon after instruction and the majority accurately represented both the waning and waxing sequences. All of the students stated that the moon moves through a predictable pattern of appearance after instruction. Although the Trundle, Atwood, and Christopher's study did not ask students about how long it takes for the change in appearance of the moon (and thus we cannot directly compare these students to our learning progression) this work is promising for demonstrating how students may improve their ability to describe the changing shape of the moon.

\section{Summary and Conclusions}

The work described here advances the literature by presenting a fine grained description of a set of learning trajectories on apparent celestial motion developed from students' ideas across various ages and then tested against an instructional intervention that could eventually lead to a full learning progression on celestial motion. The results demonstrate that traditional instruction and observations of the world are not sufficient to help students move beyond an intermediate level of understanding, even by adulthood, in this concept area; targeted instruction is necessary. More importantly, we demonstrate how focused instruction can move students to develop more sophisticated understandings of these topics.

Our initial work towards the development of a learning progression for celestial motion also advances the field of astronomy education by presenting a new way of moving the field forward. Astronomy education research has an extensive history of uncovering non-normative ideas and, to a lesser extent, on examining how specific instructional interventions may improve students' understanding (Adams \& Slater, 2000; Bailey \& Slater, 2003; Kavanagh, 2007). The development of these learning trajectories places new emphasis on the importance of students learning these patterns of celestial motion in a way that is different from current practice in school. Recognizing that students may need to develop increasingly sophisticated ways of describing the sun, moon, and stars from their perspective may help improve their ability to explain these phenomena beyond instruction that primarily addresses the rotation and revolution of the earth.

A learning progression can be thought of as a rule or a scale that may be used to measure a student's understanding relative to conceptual goal. With the intermediate levels in place on the scale, we can make instructional decisions to move students to more sophisticated ways of understanding (Duschl et al., 2007; Smith et al., 2006). Using this approach to test the use of learning trajectories, we examined how planetarium instruction, which utilized KLTs, was successful in improving early elementary students' descriptions of apparent celestial motion. The learning trajectories provided a clear scale on which to articulate the levels which these students' attained as they moved to more sophisticated ways of describing the motions of the sun, moon, and stars. This approach also demonstrated how the instructional intervention moved elementary students' descriptions to levels beyond what the majority of middle school students had achieved without targeted instruction. The planetarium instruction gave the students an opportunity to visualize these motions from their own perspective in a way that is not readily available in most classrooms; 3-D planetarium technology is not easily duplicated within a classroom and many teachers do not fully understand these motions themselves (Mant \& Summers, 1993; Plummer et al., accepted). We have also used the learning 
progression framework to identify the higher levels that were infrequently attained by students who attended this planetarium program, suggesting where additional instruction will be necessary. A learning progression could become a tool to facilitate a discussion between teachers and planetarium directors to identify where teachers can continue instruction when students return to the classroom. Research on informal education has emphasized the importance of making field trip experiences an integrated part of the classroom for meaningful learning outcomes (Griffin \& Symington, 1997; Rennie \& McClafferty, 1995).

The next step in this work is to develop a full learning progression for celestial motion, combining students' descriptions of observable phenomenon with the underlying explanations grounded in the motion of celestial objects. In this study we have discussed the apparent motion of the sun, moon, and stars as separate learning trajectories. In a full learning progression, increasing sophistication begins with applying the earth's rotation to explain the rising and setting of the sun, moon, and stars (Levels 1 and 2 in the learning trajectories for the sun and moon, and Levels 2 and 3 for the stars; Plummer \& Slagle, 2009). The observational trajectories connect to more advanced concepts in celestial motion at the higher levels such as phases of the moon and the seasons. Briggs, Alonzo, Schwab, and Wilson's (2006) created and tested a single construct map (a construction similar to a learning trajectory) describing the "Earth in the Solar System" concepts. The researchers' goal "was to create a single continuum to be used to describe students' understanding" (Briggs et al., 2006, p. 40) of the day/night cycle, phases of the moon, and the seasons. While we agree that the ultimate goal should be to understand these phenomena in a unified framework, we suggest that a productive direction towards learning progression development in elementary astronomy is through the creation and testing of separate sets of learning trajectories organized according to the nature of students' cognition with respect to the conceptual framework (an approach also suggested by Wilson, 2009). The complexity of the topics associated with celestial motion and the need for understanding how instruction can be used to increase the sophistication of students' ideas requires a multi-facetted progression where we may consider students' development along the learning trajectories created here as well as trajectories describing students' explanations. For example, the full progression would combine aspects of the phases of the moon such that Level 3 (the moon rises later every day) of learning trajectory 2 (moon's apparent motion) and the entire description in learning trajectory 4 (moon's changing appearance) are explained in increasing sophistication using the orbit of the moon in conjunction with the position of the earth and sun to explain why the moon appears to rise later each day and changes appearance.

Another learning trajectory within this full learning progression would address the explanation for the seasons; research is needed examine the connection between learning trajectory 1 (apparent motion of the sun) and how students learn to explain mechanism that causes the seasons. Previous studies of children and adults' knowledge of the seasons, both with and without instruction, have primarily focused on how they explain this phenomenon in terms of the tilt of the earth without assessing how subjects describe what we can observe or experience (Atwood \& Atwood, 1996; Parker \& Heywood, 1998; Trumper, 2001a,b,c; however, see Trumper (2006) for a study of an observational approach towards learning about the seasons). Because the sun's apparent motion is an observable phenomenon, this aspect of the seasons may be more appropriate for children to learn first than the more abstract aspects of the seasons that combine understanding the earth's rotation, tilt and orbit. Planetarium instruction improves children's ability to describe these changes, but waiting until upper elementary school to study these changes may provide a better foundation for when they are preparing to learn to explain the seasons in the classroom.

Additional research is needed that extends instructional time beyond a single planetarium visit and makes connections to the classroom. This will be necessary to understand the use of instruction to produce lasting effects as measured by the progression and to combine this with the explanations of celestial motion. Instruction that takes place in the classroom or uses students' own observations may offer new insights into how students progress in this area and demonstrate alternative successful paths of learning.

The authors wish to thank Valerie Zahm for providing the illustration in Figure 1. This research was conducted as part of the Center for Curriculum Materials in Science (CCMS), contract grant number, ESI 0227557 to the American Association for the Advancement of Science (AAAS) for CCMS. Any opinions expressed in this work are those of the authors and do not necessarily represent either those of the funding agency or Arcadia University and the University of Michigan. 


\section{References}

American Association for the Advancement of Science. (1993). Benchmarks for science literacy. New York: Oxford University Press.

Adams, J.P., \& Slater, T.F. (2000). Astronomy in the national science education standards. Journal of Geoscience Education, 48(1), 39-45.

Agan, L., \& Sneider, C. (2004). Learning about the Earth's shape and gravity: A guide for teachers and curriculum developers. Astronomy Education Review, 2(2), 90-117.

Anderson, C.W. (2008, March). Learning progressions for environmental science literacy. Paper presented at the meeting of the National Association for Research in Science Teaching, Baltimore, MD.

Atwood, R.K., \& Atwood, V.A. (1996). Preservice elementary teachers' conceptions of the causes of seasons. Journal of Research in Science Teaching, 33(5), 553-563.

Bailey, J.M., \& Slater, T. (2003). A review of astronomy education research. Astronomy Education Review, 2(2), $20-45$.

Barnett, M., \& Morran, J. (2002). Addressing children's alternative frameworks of the moon's phases and eclipses. International Journal of Science Education, 24(8), 859-879.

Baxter, J. (1989). Children's understanding of familiar astronomical events. International Journal of Science Education, 11, 502-513.

Briggs, D.C., Alonzo, A.C., Schwab, C., \& Wilson, M. (2006). Diagnostic assessment with ordered multiple-choice items. Educational Assessment, 11(1), 33-63.

Catley, K., Lehrer, R., \& Reiser, B. (2005). Tracing a prospective learning progression for developing understanding of evolution. Paper commissioned by the National Academies Committee on Test Design for K-12 Science Achievement. Washington, DC: National Academies.

Clark, J.M., \& Paivio, A. (1991). Dual coding theory and education. Educational Psychology Review, 3(3), 149-210.

Clements, D.H., \& Sarama, J. (2004). Learning trajectory in mathematics education. Mathematical Thinking and Learning, 6(2), 81-90.

Corcoran, T.B., Mosher, F.A. \& Rogat, A.O. (2009). Learning progressions in science: An evidence-based approach to reform. (CPRE Report). Philadelphia, PA: Consortium for policy Research in Education.

Diakidoy, I.-A.N., \& Kendeou, P. (2001). Facilitating conceptual change in astronomy: a comparison of the effectiveness of two instructional approaches. Learning and Instruction, 11, 1-20.

Duncan, R.G., Rogat, A., \& Yarden, A. (2009). A learning progression for deepening students' understandings of modern genetics across the 5th-10th grades. Journal of Research in Science Teaching, 46(6), 655-674.

Duschl R.A., Schweingruber H.A., \& Shouse A. (Eds.), (2007). Taking science to school: Learning and teaching science in grades K-8. Washington, D.C.: National Academies Press.

Gravemeijer, K. (2004). Local instruction theories as means of support for teachers in reform mathematics education. Mathematical Thinking and Learning, 6(2), 105-128.

Griffin, J., \& Symington, D. (1997). Moving from task-oriented to learning-oriented strategies on school excursions to museums. Science Education, 81, 763-779.

Heritage, M., (2008). Learning progressions: Supporting instruction and formative assessment. Paper prepared for the Council of Chief State School Officers (CCSSO), Washington, DC. Retrieved May 27, 2008, from http://www.nciea.org/.

Hmelo-Silver, C.E., \& Duncan, R.G. (2009). Learning progressions. Journal of Research in Science Teaching, 46(6): 606-609.

Kavanagh, C. (2007 , September). Astronomy education research bibliography. Paper presented at the Astronomy Education Research Symposium, Tufts University, Medford, MA.

Kavanagh, C., Agan, L., \& Sneider, C. (2005). Learning about phases of the moon and eclipses: Guide for Teachers and Curriculum Developers. Astronomy Education Review, 4(1), 34. 167.

Lightman, A., \& Sadler, P. (1993). Teacher predictions versus actual student gains. The Physics Teacher, 31, 162-

Mant, J., \& Summers, M. (1993). Some primary-school teachers' understanding of Earth's place in the universe. Research Papers in Education, 8(1), 101-129.

Mohan, L., Chen, J., \& Anderson, W.A. (2009). Developing a multi-year learning progression for carbon cycling in socio-ecological systems. Journal of Research in Science Teaching, 46(6), 675-698.

National Research Council. (1996). National science education standards. Washington, DC: National Academy Press.

Parker, J., \& Heywood, D. (1998). The earth and beyond: developing primary teachers' understanding of basic astronomical events. International Journal of Science Education, 20(5), 503-520. 
Plummer, J.D. (2009a). A cross-age study of children's knowledge of apparent celestial motion. International Journal of Science Education, 31(12), 1571-1605.

Plummer, J.D. (2009b). Early elementary students' development of astronomy concepts in the planetarium. Journal of Research in Science Teaching, 46(2), 192-209.

Plummer, J.D., \& Slagle, C. (2009 , April). Children explaining celestial motion: Development of a learning progression. Paper presented at the annual meeting of the National Association for Research in Science Teaching, Garden Grove, CA.

Plummer, J.D., Zahm, V., \& Rice, R. (accepted). Inquiry and astronomy: Preservice teachers' investigations of celestial motion. Journal of Science Teacher Education.

Rennie, L.J., \& McClafferty, T. (1995). Using visits to interactive science and technology centers, museums, aquaria, and zoos to promote learning in science. Journal of Science Teacher Education, 6(4), 175-185.

Roberts, R., \& Aman, C. (1993). Developmental differences in giving directions: Spatial frames of reference and mental rotation. Child Development, 64(4), 1258-1270.

Sharp, J.G. (1996). Children's astronomical beliefs: a preliminary study of year 6 children in south-west England. International Journal of Science Education, 18(6), 685-712.

Shin, N., Stevens, S.Y., \& Krajcik, J. (accepted). Tracking student learning over time using Construct-Centered Design. In S. Rodrigues Routledge. (Ed.), Using analytical frameworks for classroom research: collecting data and analysing narrative. London: Taylor \& Francis.

Simon, M.A. (1995). Reconstructing mathematics pedagogy from a constructivist perspective. Journal for Research in Mathematics Education, 26, 114-145.

Simon, M.A., \& Tzur, R. (2004). Explicating the role of mathematical tasks in conceptual learning: An elaboration of the hypothetical learning trajectory. Mathematical Thinking and Learning, 6(2), 91-104.

Smith, C.L., Wiser, M., Anderson, C.W., \& Krajcik, J. (2006). Implications of research on children's learning for standards and assessment: A proposed learning progression for matter and the atomic molecular theory. Measurement: Interdisciplinary Research and Perspective, 14, (1\&2):1-98.

Stahly, L.L., Krockover, G.H., \& Shepardson, D.P. (1999). Third grade students' ideas about the lunar phases. Journal of Research in Science Teaching, 36(2), 159-177.

Stevens, S.Y., Delgado, C., \& Krajcik, J.S. (2009). The development of an empirically derived multi-dimensional learning progression for atomic structure and inter-atomic interactions. Journal of Research in Science Teaching, online in advance of print.

Songer, N.B., Kelcey, B., \& Gotwals, A.W. (2009). How and when does complex reasoning occur? Empirically driven development of a learning progression focused on complex reasoning about biodiversity. Journal of Research in Science Teaching, 46(6), 610-631.

Talanquer, V. (2009). On cognitive constraints and learning progressions: The case of "structure of matter". International Journal of Science Education, 31(15), 2123-2136.

Trumper, R. (2001a). A cross-age study of junior high school students' conceptions of basic astronomy concepts. International Journal of Science Education, 23(11), 1111-1123.

Trumper, R. (2001b). A cross-age study of senior high school students' conceptions of basic astronomy concepts. Research in Science \& Technological Education, 19(1), 97-109.

Trumper, R. (2001c). A cross-college age study of science and nonscience students' conceptions of basic astronomy concepts in preservice training for high-school teachers. Journal of Science Education and Technology, 10(2), 189-195.

Trumper, R. (2006). Teaching future teachers basic astronomy concepts—seasonal change — at a time of reform in science. Journal of Research in Science Teaching, 43(9), 879-906.

Trundle, K.C., Atwood, R.K., \& Christopher, J.E. (2002). Preservice elementary teachers' conceptions of moon phases before and after instruction. Journal of Research in Science Teaching, 39(7), 633-658.

Trundle, K.C., Atwood, R.K., \& Christopher, J.E. (2006). Preservice elementary teachers' knowledge of observable moon phases and pattern of change in phases. Journal of Science Teacher Education, 17(2), 87-101.

Trundle, K.C., Atwood, R.K., \& Christopher, J.E. (2007a). A longitudinal study of conceptual change: preservice elementary teachers' conceptions of moon phases. Journal of Research in Science Teaching, 44(2), 303-326.

Trundle, K.C., Atwood, R.K., \& Christopher, J.E. (2007b). Fourth-grade elementary students' conceptions of standards-based lunar concepts. International Journal of Science Education, 29(5), 595-616.

Vosniadou, S., \& Brewer, W.F. (1994). Mental models of the day/night cycle. Cognitive Science, 18, 123-183.

Wilson, M. (2005). Constructing measures. Mahwah, NJ: Lawrence Earlbaum Associates.

Wilson, M. (2009). Measuring progressions: Assessment structures underlying a learning progression. Journal of Research in Science Teaching, 46(6), 716-730. 


\section{Appendix}

Interview Protocol Questions

(1) Where is the sun first thing in the morning? At 10 O'clock? At noon? In the afternoon? What happens to the sun at the end of the day? Show me again what the sun does throughout the entire day. (Used for both summer and winter)

(2) Where is the sun when it is highest in the sky? Is that directly overhead? (Used for both summer and winter)

(3) (Summer) Where is the sun when it is highest in the sky? (Winter) Where is the sun when it is highest in the sky? Is that the same as the summer?

(4) Can you draw a picture of the moon? Does the moon ever look different than that? How long does it take for the shape of the moon to change?

(5) Does the shape of the moon change during the course of one night?

(6) Can we ever see the moon during the day?

(7) Let's pretend that it's night. Where might we see the moon when it first gets dark out? Where would we see the moon at midnight? If we went out just before sunrise, where will the moon be? What happens to the moon when the sun comes up again? Can you show me again what the moon does during the night?

(8) Let's pretend that it's just gotten dark outside and there is a bright star up there. Where would we see that star at midnight? Would it be in the same place?

(9) If we went outside just before sunrise would we see the same stars as we saw just after sunset?

(10) Why don't we see any stars during the daytime?

(11) What is going to happen to make it daytime again?

This interview protocol first appeared in Plummer (2009a). 